\title{
Research Paper: The Relationships Between Some Physical Fitness Factors and Muscle Damage in People With Intellectual Disabilities
}

Hojjatollah Siavoshi $^{*}$ (D), Hamid Agha Alinejad ${ }^{2}$ (D), Ali Kashi ${ }^{3}$ (D), Mohammad Ali Samavati Sharif ${ }^{4}$ (D), Masoumeh Helalizadeh ${ }^{1}$ (D)

1. Department of Exercise Physiology, Sports Medicine Research Center, Sport Sciences Research Institute, Tehran, Iran.

2. Department of Physical Education and Exercise Physiology, Tarbiat Modares University, Tehran, Iran.

3. Department of Motor Behavior, Sports Medicine Research Center, Sport Science Research Institute, Tehran, Iran.

4. Department of Exercise Physiology, Faculty of Sport Sciences, Bu-Ali Sina University, Hamadan, Iran.

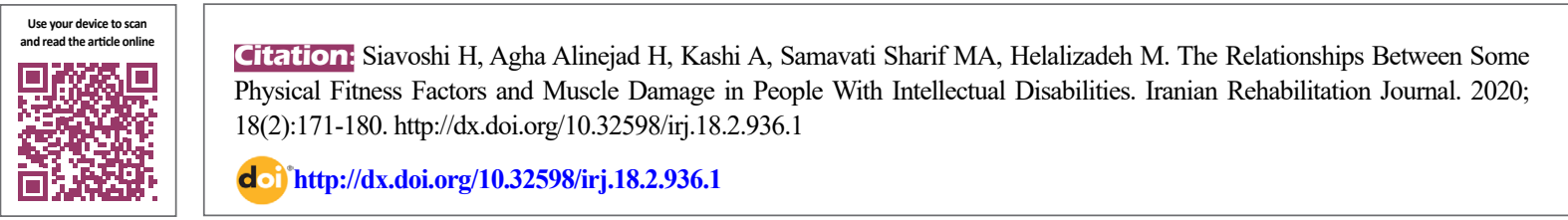

Article info:

Received: 30 Jul 2019

Accepted: 12 Feb 2020

Available Online: 01 Jun 2020

Keywords:

Canadian test, Strength,

Endurance, Flexibility,

Cardiorespiratory, $\mathrm{VO}_{2 \max }$

\section{ABSTRACT}

Objectives: The physical component of tasks can be a problem because of muscle weakness; therefore, this research was performed to investigate the relationships between some physical fitness factors and muscle damage enzyme levels in people with mild Intellectual Disabilities (ID).

Methods: In this cross-sectional study, 314 students with ID (Body Mass Index [BMI]: $23.42 \pm 4.84 \mathrm{~kg} / \mathrm{m}^{2}$ ), after measuring their anthropometric variables (height, weight, and BMI), performed the Canadian Standardized Test of Fitness (CSTF). This test includes flexibility (sit and reach test), muscle endurance (Push-ups and Sit-ups tests), muscle strength (Hand-grip test), and cardiorespiratory endurance (Canada Home Fitness test). Then saliva samples were collected from 20 subjects who were homogeneous for age (Mean \pm SD: 20.30 \pm 2.27 years), sex (male only), and type of ID, for measuring their saliva levels of Creatine Phosphate Kinase (CPK), Lactate Dehydrogenase (LDH), and C-reactive Protein (CRP). Data were analyzed by the Pearson correlation coefficient and linear and nonlinear regressions $(\mathrm{P}<0.05)$.

Results: The findings indicated significant relationships between some of the physical fitness factors and some enzymes of muscle damage $(\mathrm{P}<0.05)$. The results indicated significant relationships between $\mathrm{CPK}$, with push-ups, sit-ups, and hand-grip strength, as well as between the LDH with push-ups and CRP with sit-ups and hand-grip strength $(\mathrm{P}<0.05)$.

Discussion: According to the results of the present research, CPK, LDH, and CRP saliva levels in males with an ID have a significant relationship with some of the physical fitness components. Also, the results of the present research have provided equations for estimating CPK, LDH, and CRP saliva levels through CSTF battery test scores in people who have an educable ID.

* Corresponding Author:

Hojjatollah Siavoshy, PhD. Candidate

Address: Department of Exercise Physiology, Sports Medicine Research Center, Sport Sciences Research Institute, Tehran, Iran.

Tel: +98 (81) 33230528

E-mail: seiavoshy@gmail.com 


\section{Highlights}

- There is a significant and negative relationship between CPK levels with the push-up, sit-up, and hand-grip strength of physical fitness factors.

- There is a significant and negative relationship between LDH levels with push-up physical fitness factor.

- There is a significant and negative relationship between CRP levels with push-up and hand-grip strength physical fitness factors.

\section{Plain Language Summary}

Findings of the current research have shown relationships between some physical fitness components and some muscle damage factors in people with intellectual disabilities. Also, according to the results of the present research, the amount of muscle tissue damage and muscle destruction may be predicted by measuring some physical fitness factors in males with intellectual disabilities.

\section{Introduction}

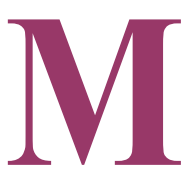

any scholars believe that inflammation processes (even in systematic or general type) are among the underlying causes that prepare the ground for the beginning of atherosclerosis and Cardiovascular Disorders (CVD). Nevertheless, since the last decades, scholars have paid attention to inflammatory biomarkers, that predict the risk of CVD with more precision and accuracy. In this regard, the C-reactive Protein (CRP) is known as one of the most strong and sensitive independent predictors of CVD risk $[1,2]$.

On the other hand, one of the procedures to measure oxidative stress that is provoked by cellular destruction is to assess the amount of anti-oxidative enzymes secretion. Lactate Dehydrogenase (LDH) and Creatine Phosphate Kinase (CPK) are among enzymes that are known as oxidative stress markers [1-3]. Glycolysis pathway reactions and actions besides hydrogen's ions increment due to intracellular $\mathrm{pH}$ plunge, some lactates leave muscular cells with hydrogen's ions and this impacts extracellular buffer capacity that triggers movement in hydrogen's ions. However, this is due to the decrement in intracellular $\mathrm{pH}$ to the point which stimulates disruption in cellular proficiency. In other words, oxidative stress disrupts cellular membrane performance and this might be estimated by evaluation of CK plasma levels (following the membrane damage, $\mathrm{CK}$ secretes into serum plasma) $[2,3]$.

Physical activity and physical fitness are important for everybody, including people with Intellectual Disabilities (ID) [4, 5]. Because of the unique condition of people with ID and their cognitive and motor function impairments, these individuals are less active at all stages of life compared with healthy individuals [6]. Various studies have reported that people with intellectual disabilities need physical activity because these individuals generally have very low levels of physical fitness [6-11]

However, there are few studies on the relationship between physical fitness factors and muscle damage factors of students with ID. So the question arises whether there is a relationship between physical fitness factors and muscle destruction factors in this population. Therefore, the present study aimed to investigate the relationships between some physical fitness factors and muscle damage in people with ID.

\section{Methods}

\section{Study Participants}

In the present study, using Morgan's table, 314 individuals with ID (Mean \pm SD age: $18.53 \pm 2.6$ years; Mean \pm SD weight: $63.47 \pm 14.87 \mathrm{~kg}$; Mean \pm SD BMI: $23.42 \pm 4.84 \mathrm{~kg} /$ $\mathrm{m}^{2}$ ), with an educable ID were selected from special education schools in the cities of Hamadan, Malayer, Nahavand, Tuyserkan, Asadabad, Razan, and Bahar, in Hamadan Province, Iran (Table 1). The inclusion criteria were studying in the special schools (middle or high schools), having an educable IQ (50-70), being able to perform simple verbal commands in Persian, and being ascertained by asking parents to fill out the screening procedure (7-item physical activity readiness questionnaire [PAR-Q]) and agreeing to participate by returning signed consent forms to the researcher, on behalf of their child. The experiment was approved by the 
Table 1. General characteristics of the study participants

\begin{tabular}{|c|c|c|c|c|c|}
\hline \multirow{2}{*}{\multicolumn{2}{|c|}{ variables }} & \multicolumn{4}{|c|}{ Mean $\pm S D$ (No.) } \\
\hline & & ID & SD & PD & ADHD \\
\hline \multirow{3}{*}{ IQ (n) } & Low & 70 & 7 & 6 & 1 \\
\hline & Medium & 92 & 8 & 6 & 3 \\
\hline & High & 100 & 3 & 17 & 1 \\
\hline \multirow{3}{*}{$\operatorname{sex}(n)$} & Female & 90 & 12 & 12 & 1 \\
\hline & Male & 172 & 6 & 17 & 4 \\
\hline & (y) & $18.54 \pm 2.44(262)$ & $19.28 \pm 3.85(18)$ & $18.45 \pm 2.50(29)$ & $15.60 \pm 1.34(5)$ \\
\hline \multicolumn{2}{|c|}{ Height $(\mathrm{cm})$} & $165.89 \pm 11.02(262)$ & $146.17 \pm 8.75(18)$ & $162.43 \pm 8.04(29)$ & $168.60 \pm 7.89(5)$ \\
\hline \multicolumn{2}{|c|}{ Weight (kg) } & $64.97 \pm 15.13(262)$ & $60.87 \pm 10.97(18)$ & $53.33 \pm 10.12(29)$ & $53.22 \pm 8.83(5)$ \\
\hline \multicolumn{2}{|c|}{$\mathrm{BMI}\left(\mathrm{kg} / \mathrm{m}^{2}\right)$} & $23.53 \pm 4.71(262)$ & $28.51 \pm 4.62(18)$ & $20.14 \pm 3.04(29)$ & $18.62 \pm 1.72(5)$ \\
\hline \multicolumn{2}{|c|}{ Sit and reach $(\mathrm{cm})$} & $19.94 \pm 9.72(246)$ & $25.58 \pm 10.66(18)$ & $14.22 \pm 8.44(23)$ & $20.60 \pm 11.38(5)$ \\
\hline \multicolumn{2}{|c|}{ Push-up (n) } & $12.04 \pm 8.56(220)$ & $13.38 \pm 8.93(16)$ & $7.08 \pm 5.96(12)$ & $12.00 \pm 3.61(3)$ \\
\hline \multicolumn{2}{|c|}{ Sit-up (n/min) } & $19.70 \pm 9.54(245)$ & $17.06 \pm 10.02(17)$ & $17.37 \pm 8.69(19)$ & $10.50 \pm 7.33(4)$ \\
\hline \multicolumn{2}{|c|}{ Hand-grip (lb) } & $33.38 \pm 12.53(248)$ & $20.33 \pm 7.01(12)$ & $30.10 \pm 8.72(21)$ & $26.75 \pm 17.50(4)$ \\
\hline \multicolumn{2}{|c|}{ Heart rate $(\mathrm{p} / \mathrm{min})$} & $165.23 \pm 12.99(156)$ & $165.00 \pm 13.22(8)$ & $165.29 \pm 4.54(7)$ & $156.00 \pm 33.94(2)$ \\
\hline \multicolumn{2}{|c|}{$\mathrm{VO}_{2 \max }(\mathrm{mL} / \mathrm{kg} \cdot \min )$} & $44.22 \pm 6.45(156)$ & $41.43 \pm 6.34(8)$ & $39.67 \pm 5.16(7)$ & $51.18 \pm 5.53(2)$ \\
\hline \multicolumn{2}{|c|}{ CPK (u/L) } & $17.00 \pm 11.47(20)$ & - & - & - \\
\hline \multicolumn{2}{|c|}{$\mathrm{LDH}(\mathrm{u} / \mathrm{L})$} & $473.25 \pm 312.54(20)$ & - & - & - \\
\hline \multicolumn{2}{|c|}{$\mathrm{CRP}(\mathrm{mg} / \mathrm{L})$} & $42.07 \pm 25.07(20)$ & - & - & - \\
\hline
\end{tabular}

Iranian Rehabilitation Journa

IQ: Intelligence Quotient; ID: Intellectual Disability; SD: Syndrome Down; PD: Physical-motor Disability; ADHD: Attention Deficit Hyperactivity Disorder; BMI: Body Mass Index; $\mathrm{VO}_{2 \max }$ : Maximal Oxygen Consumption; CPK: Creatine Phosphokinase; LDH: Lactate Dehydrogenase; CRP: C-reactive Protein

Ethics Committee of the Tehran Sport Sciences Research Institute in Iran. The exclusion criteria were any medical ban on exercise activities such as cardiovascular problems, use of any drug or substance that affects their physical activity, and having disabilities such as blindness, deafness along with intellectual disabilities. The chronological and intelligence age (intelligence quotient; IQ) of the participants were also obtained through their education records.

Because of the concerns about formal intelligence testing in these people [9], parent perceptions were used to give a general indication of the ID level (IQ) of their children. The ID level (IQ) of each subject was described as low, medium, or high as perceived by their parents.

Some participants in the present research were unable to perform tests completely or did them incorrectly. So, the number of people who performed these tests was different in some subscales (sit and reach test: 113 females and 179 males; push-up test: 102 females and 149 males; sit-up tests: 112 females and 173 males; hand-grip test: 101 females and
184 males; and cardio-respiratory endurance test $\left(\mathrm{VO}_{2 \max }\right)$ : 71 females and 102 males).

\section{Study procedures}

At first, the height, weight (by Beurer Scale, Model: MS 01.3; Made in Germany), and body mass index (BMI) of the students were measured and calculated. Then, flexibility (by sit and reach test), muscle endurance (by push-up and sit-up tests), muscle strength (by a hand-grip test), and cardio-respiratory endurance $\left(\mathrm{VO}_{2 \max }\right.$; by Canadian home fitness test) were measured by the Canadian standardized test of fitness (CSTF) battery test, according to the test manual [12]. This battery test was first designed and standardized in Canadian individuals in 1981 [13, 14]; and then standardized in Canadian ID people [14-17] and Iranian ID people [18].

\section{Clinical measurements}

In this study, after the mouth had been rinsed thoroughly with distilled water, salivary samples were collected from 
20 subjects who were homogeneous for age (Mean \pm SD age: $20.30 \pm 2.27$ years), sex (male only), and type of ID (without Down syndrome, Attention Deficit Hyperactivity Disorder (ADHD), etc.), for measuring salivary levels of CPK, LDH, and CRP (Table 1). The maximum standard deviation in CSTF test subscales in a similar population was 10.21 [18]. Therefore, to maintain the power of $80 \%$ with a significance level of $0.05,20$ subjects are required in this research.

\section{Data analysis}

To determine the relationship between muscle damage and physical fitness factors, first of all, the study variables were analyzed using the K-S and Levene's tests to check the normality and homoscedasticity of data distribution and to determine whether parametric tests should be used or nonparametric ones. In our study, after checking for normality, for normally distributed data, the Pearson correlation coefficient was used to investigate the relationship between the variables. Subsequently, linear and nonlinear regressions were used to determine the equations and formulas. All data were analyzed in SPSS V. 21 at a significant level of $0.05(\mathrm{P}<0.05)$.

\section{Results}

The findings indicated significant relationships between some of the physical fitness factors and CPK, LDH, and CRP levels (Table 2 and Figure 1). The following Table and Figure present the correlations between these components.

There is a significant negative relationship between $\mathrm{CPK}$ levels and push-up test $(\mathrm{F}=6.575 ; \mathrm{P}=0.020)$. A nonlinear regression (Power regression) was used to design an equation

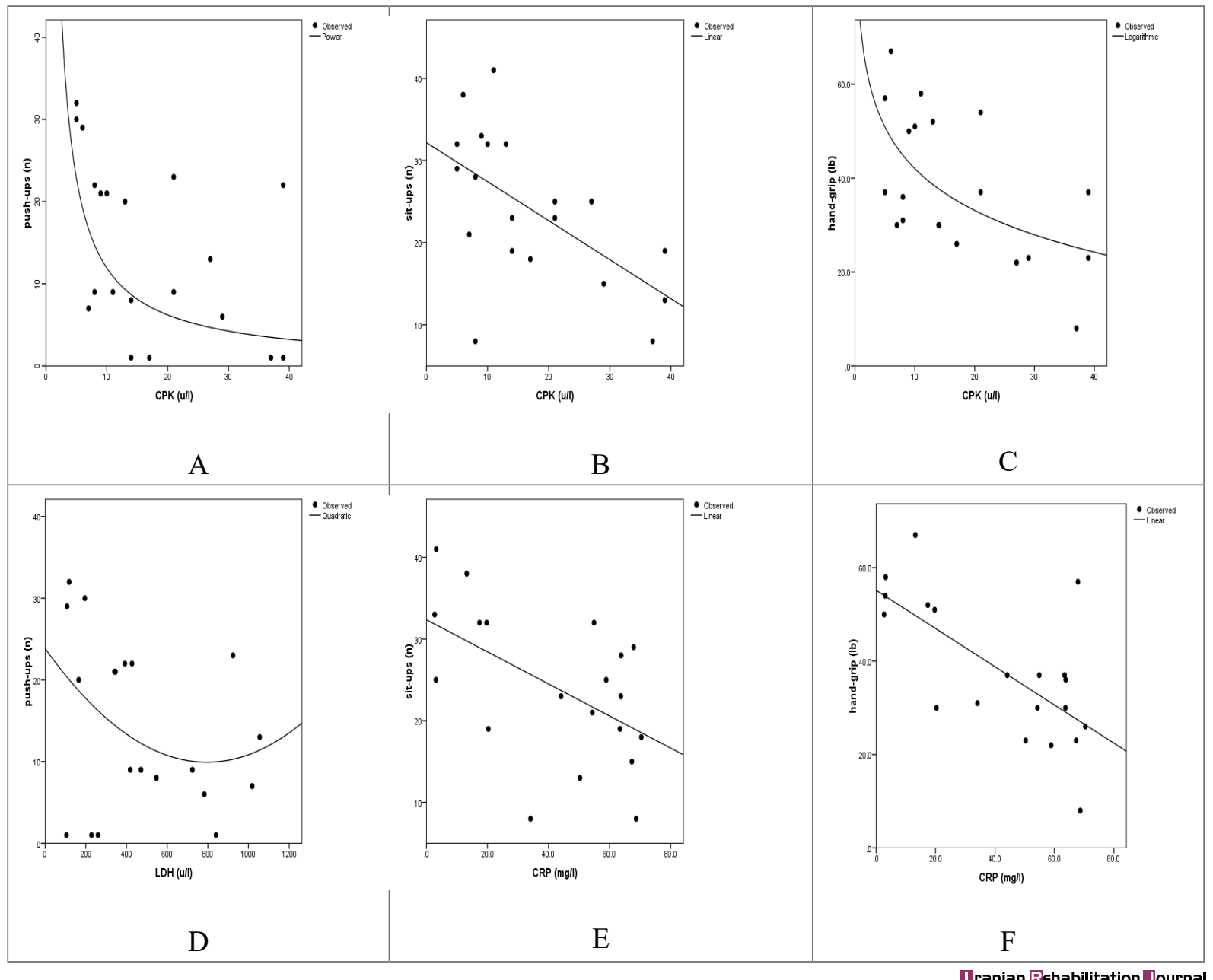

Figure 1. The relationship between saliva levels

A: CPK and push-up test by nonlinear regression (power regression); B: CPK and sit-up test by linear regression; C: CPK and hand-grip strength by nonlinear regression (logarithmic regression); D: LDH and push-up test by nonlinear regression (quadratic regression); E: CRP and sit-up test by linear regression; F: CRP and hand-grip strength test by linear regression 
Table 2. The correlations between damage muscle and physical fitness factors (the Pearson's correlation coefficient)

\begin{tabular}{|c|c|c|c|c|c|c|c|c|c|c|c|c|c|}
\hline \multicolumn{2}{|c|}{ Variables } & $1 Q^{5}$ & Age & Height & Weight & BMI & SR & PU & SU & HG & $\mathrm{VO}_{2 \max }$ & CPK & LDH \\
\hline \multirow{3}{*}{$\bar{\alpha}$} & $r$ & 1.000 & $0.126^{*}$ & $-0.133^{* *}$ & -0.083 & -0.018 & $-0.305^{* *}$ & $-0.341^{* *}$ & $-0.345^{* *}$ & -0.045 & 0.033 & 0.403 & 0.371 \\
\hline & $\mathrm{P}$ & . & 0.015 & 0.010 & 0.109 & 0.731 & 0.000 & 0.000 & 0.000 & 0.399 & 0.632 & 0.078 & 0.107 \\
\hline & $\mathrm{n}$ & 376 & 376 & 376 & 376 & 376 & 354 & 313 & 347 & 347 & 218 & 20 & 20 \\
\hline \multirow{3}{*}{ 営 } & $r$ & $0.126^{*}$ & 1 & 0.070 & $0.170^{* *}$ & $0.163^{* *}$ & $-0.170^{* *}$ & $-0.163^{* *}$ & $-0.260^{* *}$ & $0.135^{*}$ & -0.010 & -0.246 & $-0.582^{* *}$ \\
\hline & $\mathrm{P}$ & 0.015 & & 0.173 & 0.001 & 0.002 & 0.001 & 0.004 & 0.000 & 0.012 & 0.881 & 0.295 & 0.007 \\
\hline & $\mathrm{n}$ & 376 & 376 & 376 & 376 & 376 & 354 & 313 & 347 & 347 & 218 & 20 & 20 \\
\hline \multirow{3}{*}{ 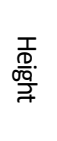 } & $r$ & $-0.133^{* *}$ & 0.070 & 1 & $0.516^{* *}$ & -0.094 & 0.067 & 0.085 & $0.217^{* *}$ & $0.379^{* *}$ & $0.201^{* *}$ & 0.344 & -0.018 \\
\hline & $\mathrm{P}$ & 0.010 & 0.173 & & 0.000 & 0.068 & 0.207 & 0.136 & 0.000 & 0.000 & 0.003 & 0.137 & 0.941 \\
\hline & $\mathrm{n}$ & 376 & 376 & 376 & 376 & 376 & 354 & 313 & 347 & 347 & 218 & 20 & 20 \\
\hline \multirow{3}{*}{ 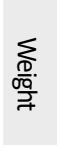 } & $r$ & -0.083 & $0.170^{* *}$ & $0.516^{* *}$ & 1 & $0.796 * *$ & $0.142^{* *}$ & $-0.120^{*}$ & -0.080 & $0.263^{* *}$ & $-0.229 * *$ & 0.047 & 0.193 \\
\hline & $P$ & 0.109 & 0.001 & 0.000 & & 0.000 & 0.007 & 0.034 & 0.137 & 0.000 & 0.001 & 0.845 & 0.415 \\
\hline & $\mathrm{n}$ & 376 & 376 & 376 & 376 & 376 & 354 & 313 & 347 & 347 & 218 & 20 & 20 \\
\hline \multirow{3}{*}{$\underline{\text { 罗 }}$} & $r$ & -0.018 & $0.163^{* *}$ & -0.094 & $0.796^{* *}$ & 1 & $0.126^{*}$ & $-0.201^{* *}$ & $-0.255^{* *}$ & 0.039 & $-0.423^{* *}$ & -0.217 & 0.237 \\
\hline & $\mathrm{P}$ & 0.731 & 0.002 & 0.068 & 0.000 & & 0.017 & 0.000 & 0.000 & 0.471 & 0.000 & 0.358 & 0.315 \\
\hline & $\mathrm{n}$ & 376 & 376 & 376 & 376 & 376 & 354 & 313 & 347 & 347 & 218 & 20 & 20 \\
\hline \multirow{3}{*}{ 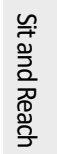 } & $r$ & $-0.305^{* *}$ & $-0.170^{* *}$ & 0.067 & $0.142^{* *}$ & $0.126^{*}$ & 1 & $0.264^{* *}$ & $0.352^{* *}$ & $0.219 * *$ & -0.052 & -0.304 & -0.318 \\
\hline & $\mathrm{P}$ & 0.000 & 0.001 & 0.207 & 0.007 & 0.017 & & 0.000 & 0.000 & 0.000 & 0.443 & 0.192 & 0.172 \\
\hline & $\mathrm{n}$ & 354 & 354 & 354 & 354 & 354 & 354 & 305 & 335 & 328 & 216 & 20 & 20 \\
\hline \multirow{3}{*}{ 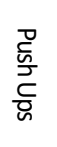 } & $r$ & $-0.341^{* *}$ & $-0.163^{* *}$ & 0.085 & $-0.120^{*}$ & $-0.201^{* *}$ & $0.264^{* *}$ & 1 & $0.514^{* *}$ & $0.178^{* *}$ & $0.181^{* *}$ & $-0.456^{*}$ & -0.312 \\
\hline & $\mathrm{P}$ & 0.000 & 0.004 & 0.136 & 0.034 & 0.000 & 0.000 & & 0.000 & 0.002 & 0.010 & 0.043 & 0.180 \\
\hline & $\mathrm{n}$ & 313 & 313 & 313 & 313 & 313 & 305 & 313 & 308 & 291 & 202 & 20 & 20 \\
\hline \multirow{3}{*}{ 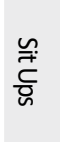 } & $r$ & $-0.345^{* *}$ & $-0.260^{* *}$ & $0.217^{* *}$ & -0.080 & $-0.255^{* *}$ & $0.352^{* *}$ & $0.514^{* *}$ & 1 & $0.349^{* *}$ & $0.145^{*}$ & $-0.591^{* *}$ & -0.204 \\
\hline & $\mathrm{P}$ & 0.000 & 0.000 & 0.000 & 0.137 & 0.000 & 0.000 & 0.000 & & 0.000 & 0.036 & 0.006 & 0.388 \\
\hline & $\mathrm{n}$ & 347 & 347 & 347 & 347 & 347 & 335 & 308 & 347 & 321 & 209 & 20 & 20 \\
\hline \multirow{3}{*}{$\begin{array}{l}\text { I } \\
\frac{O}{3} \\
\frac{2}{Q} \\
\text { 믐. }\end{array}$} & $r$ & -0.045 & $0.135 *$ & $0.379 * *$ & $0.263^{* *}$ & 0.039 & $0.219^{* *}$ & $0.178^{* *}$ & $0.349 * *$ & 1 & 0.081 & $-0.582^{* *}$ & -0.351 \\
\hline & $\mathrm{P}$ & 0.399 & 0.012 & 0.000 & 0.000 & 0.471 & 0.000 & 0.002 & 0.000 & & 0.248 & 0.007 & 0.129 \\
\hline & $\mathrm{n}$ & 347 & 347 & 347 & 347 & 347 & 328 & 291 & 321 & 347 & 207 & 20 & 20 \\
\hline & $r$ & 0.033 & -0.010 & $0.201^{* *}$ & $-0.229 * *$ & $-0.423^{* *}$ & -0.052 & $0.181^{* *}$ & $0.145^{*}$ & 0.081 & 1 & -0.018 & -0.295 \\
\hline & $\mathrm{P}$ & 0.632 & 0.881 & 0.003 & 0.001 & 0.000 & 0.443 & 0.010 & 0.036 & 0.248 & & 0.939 & 0.206 \\
\hline & $\mathrm{n}$ & 218 & 218 & 218 & 218 & 218 & 216 & 202 & 209 & 207 & 218 & 20 & 20 \\
\hline \multirow{3}{*}{ 읏 } & $r$ & 0.403 & -0.246 & 0.344 & 0.047 & -0.217 & -0.304 & $-0.456^{*}$ & $-0.591^{* *}$ & $-0.582^{* *}$ & -0.018 & 1 & 0.264 \\
\hline & $P$ & 0.078 & 0.295 & 0.137 & 0.845 & 0.358 & 0.192 & 0.043 & 0.006 & 0.007 & 0.939 & & 0.261 \\
\hline & $\mathrm{n}$ & 20 & 20 & 20 & 20 & 20 & 20 & 20 & 20 & 20 & 20 & 20 & 20 \\
\hline \multirow{3}{*}{ 후 } & $r$ & 0.371 & $-0.582^{* *}$ & -0.018 & 0.193 & 0.237 & -0.318 & -0.312 & -0.204 & -0.351 & -0.295 & 0.264 & 1 \\
\hline & $P$ & 0.107 & 0.007 & 0.941 & 0.415 & 0.315 & 0.172 & 0.180 & 0.388 & 0.129 & 0.206 & 0.261 & \\
\hline & $\mathrm{n}$ & 20 & 20 & 20 & 20 & 20 & 20 & 20 & 20 & 20 & 20 & 20 & 20 \\
\hline \multirow{3}{*}{ 赑 } & $r$ & 0.233 & -0.102 & 0.078 & 0.116 & 0.076 & -0.289 & -0.222 & $-0.534^{*}$ & $-0.677^{* *}$ & -0.214 & 0.351 & 0.094 \\
\hline & $\mathrm{P}$ & 0.322 & 0.669 & 0.742 & 0.627 & 0.752 & 0.217 & 0.347 & 0.015 & 0.001 & 0.364 & 0.129 & 0.692 \\
\hline & $\mathrm{n}$ & 20 & 20 & 20 & 20 & 20 & 20 & 20 & 20 & 20 & 20 & 20 & 20 \\
\hline
\end{tabular}

Iranian Rehabilitation \ourna

IQ: Intelligence Quotient; ID: Intellectual Disability; SD: Syndrome Down; PD: Physical-motor Disability; ADHD: Attention Deficit Hyperactivity Disorder; BMI: Body Mass Index; $\mathrm{VO}_{\max }$ : Maximal Oxygen Consumption; CPK: Creatine Phosphokinase; LDH: Lactate Dehydrogenase; CRP: C-reactive Protein.

* Correlation is significant at the 0.05 level (2-tailed); ${ }^{* *}$ Correlation is significant at the 0.01 level (2-tailed); ${ }^{\$}$ IQ was calculated with the Spearman's rho. 
Table 3. Model summary and parameter estimates

\begin{tabular}{|c|c|c|c|c|c|c|c|c|c|c|}
\hline \multicolumn{2}{|c|}{ Variables } & \multirow{2}{*}{ Regression Equation } & \multicolumn{5}{|c|}{ Model Summary } & \multicolumn{3}{|c|}{ Parameter Estimates } \\
\hline Criterion & Predictor & & $\mathbf{R}^{2}$ & $\mathbf{F}$ & df1 & df2 & Sig. & Constant & b1 & b2 \\
\hline \multirow{3}{*}{ CPK } & Push-up & Power & 0.268 & 6.575 & 1 & 18 & 0.020 & 25.526 & -0.285 & \\
\hline & Sit-up & Linear & 0.349 & 9.665 & 1 & 18 & 0.006 & 34.733 & -0.736 & \\
\hline & Hand-grip & Logarithmic & 0.388 & 11.412 & 1 & 18 & 0.003 & 69.244 & -14.749 & \\
\hline LDH & Push-up & Quadratic & 0.312 & 3.848 & 2 & 17 & 0.042 & 390.662 & 41.560 & -1.669 \\
\hline \multirow{2}{*}{ CRP } & Sit-up & Linear & 0.285 & 7.187 & 1 & 18 & 0.015 & 77.108 & -1.454 & \\
\hline & Hand-grip & Linear & 0.458 & 15.223 & 1 & 18 & 0.001 & 84.556 & -1.120 & \\
\hline
\end{tabular}

CPK: Creatinine Phosphokinase; LDH: Lactate Dehydrogenase; CRP: C-Reactive Protein

for estimating CPK levels based on push-up test scores. The resulting equations are as follows:

$$
\begin{aligned}
& \ln y=\ln a+b 1 \ln x \\
& \ln (C P K)=\ln 25.526-0.285 \ln (\text { push-up })
\end{aligned}
$$

or

$y=a x^{b l}$

$$
C P K=25.526\left(\text { push }^{\left.-u p^{-0.285}\right)}\right.
$$

There is a significant negative relationship between CPK levels with sit-up test $(\mathrm{F}=9.665 ; \mathrm{P}=0.006)$. Linear regression was used to determine an equation for estimating CPK levels from sit-up test scores. The resulting equations are as follows:

$$
\begin{aligned}
& y=a+b 1 x \\
& C P K=34.733-0.736 \text { (sit-ups) }
\end{aligned}
$$

There is a significant negative relationship between CPK levels with hand-grip strength $(\mathrm{F}=11.412$; $\mathrm{P}=0.003$ ). A nonlinear regression (logarithmic regression) was used to determine an equation for estimating CPK levels from hand-grip strength test scores. The resulting equations are as follows:

$$
\begin{aligned}
& y=a+b 1 \ln x \\
& C P K=69244-14.749 \ln (\text { hand-grip strength) }
\end{aligned}
$$

There is a significant negative relationship between LDH levels with push-up $(\mathrm{F}=3.848 ; \mathrm{P}=0.042)$. A nonlinear regression (quadratic regression) was used to determine an equation for estimating LDH levels from pushups test scores. The resulting equations are as follows:

$$
\begin{aligned}
& y=a+b 1 x+b 2 x^{2} \\
& L D H=390.662+41.560(\text { push-up })-1.669(\text { push-up })^{2}
\end{aligned}
$$

There is a significant negative relationship between CRP levels with sit-up $(\mathrm{F}=7.187 ; \mathrm{P}=0.015)$. Linear regression was used to determine an equation for estimating CRP levels from sit-up test scores. The resulting equations are as follows:

$$
\begin{aligned}
& y=a+b 1 x \\
& C R P=77.108-1.454 \text { (sit-up) }
\end{aligned}
$$

There is a significant negative relationship between CRP levels with hand-grip strength $(\mathrm{F}=15.223 ; \mathrm{P}=0.001)$. Linear regression was used to determine an equation for estimating CRP levels with hand-grip strength test scores. The resulting equations are as follows:

$$
\begin{aligned}
& y=a+b 1 x \\
& C R P=84.556-1.120 \text { (hand-grip strength) }
\end{aligned}
$$

The following Table presents the model summary and parameter estimates (Table 3):

\section{Discussion}

In this study, we investigated the relationship of CSTF battery test physical fitness components with LDH, CPK enzymes, and CRP in people with ID. The current study showed significant relationships between some of the CSTF battery test physical fitness components in people with ID with these enzymes and CRP. The findings of this research have shown that the CPK, LDH, and CRP saliva levels have significant relationships with some of the physical fitness exercises (push-up, sit-up, and handgrip strength). These findings are consistent with the results of some studies $[19,20]$; while are inconsistent 
with some other studies $[21,22]$. CPK is an enzyme in the body that is synthesized by various tissues and cell types. It is found mainly in tissues and cells that consume ATP rapidly, especially heart, brain, and skeletal muscles. Thus CPK is an important enzyme in such tissues. Furthermore, CPK is one of the muscle intracellular alactic anaerobic enzymes, so increased blood serum CPK levels reflect the CPK release from inside the muscle cell into the bloodstream.

After release into the bloodstream, CPK serum levels increase, and then it appears in the saliva. Therefore, elevated CPK levels in the blood and saliva indicate damage to muscle tissue [23]. However, CPK in the bloodstream and saliva may be elevated in some other conditions. For example, The CPK levels in bloodstream and saliva may be high in a wide range of medical conditions, including muscular dystrophy, rhabdomyolysis (severe muscle breakdown), autoimmune myositis, myocardial infarction (heart attack), and use of medicines such as statins. Furthermore, exercise increases the outflow of CPK to the bloodstream and saliva for up to one week, and this is the most common cause of elevated CPK in bloodstream and saliva [9]. Finally, elevated CPK level in the bloodstream and saliva may be related to elevated intracellular CPK levels such as what is seen in individuals of African races [2, 23]. But, because the concentration of CPK in red blood cells is not significant, CPK levels in bloodstream and saliva are not affected by hemolysis. Also, CPK in the bloodstream and saliva is not affected by liver disorders, unlike the other tested enzymes (e.g. aldolase, transaminases, lactate dehydrogenase). Therefore, elevated CPK levels represent leakage of the enzyme from the muscle cells only $[1,2]$.

A high LDH level usually indicates tissue destruction, which has various causes. Also, LDH activity is related to muscle fatigue; the production of lactate through the LDH complex works as a system to delay the onset of muscle fatigue. Nevertheless, LDH is often used as a biomarker of tissue destruction as $\mathrm{LDH}$ is abundant in red blood cells and can function as a biomarker for hemolysis. Besides, a blood sample that has been handled incorrectly can show false-positive elevated levels of LDH due to erythrocyte destruction $[1,2]$.

CRP secretion increases due to inflammation and damage to body tissues and is subsequently seen in high amounts in the saliva. The inverse relationship between salivary concentration with power (Table 2) indicates catabolism, increased muscle tissue destruction, and decreased power $[1,23]$.
Differences in the relationships between these variables can be due to test types. Also, high BMI had a negative effect on muscular strength and aerobic performance in mild ID people [20]. Flexibility is very important for physical fitness and prevention of damages during competitions or exercise programs and poor flexibility may influence other physical fitness factors. Therefore, more descriptive studies are needed to investigate all components of physical fitness. The influence of exercise training programs as a lifelong therapy must also be emphasized, given that ID people are at risk of a life of inactivity which may result in many medical problems.

\section{Conclusion}

According to the results of the present research, saliva levels of CPK, LDH, and CRP in men with ID have a significant relationship with some of the physical fitness components. However, due to gender homogenization, only male participants were used in this study to increase the internal validity of the study. Nevertheless, such a relationship may also be found in females. Therefore, future research can investigate such relationships among females as well. Also, the results of the present research have provided equations for estimating the CPK, LDH, and CRP saliva levels based on CSTF battery test scores in people who have an educable ID. It is also concluded that by measuring some fitness factors, it may be possible to predict the amount of muscle tissue damage and muscle destruction in men with ID. The present findings can be used by physicians, coaches, teachers, and parents of children with ID and all those who are somehow associated with individuals with ID. Since physical fitness assessment is a noninvasive and low-cost measurement, it can be a useful marker for identifying muscle damage levels in people with ID.

\section{Ethical Considerations}

\section{Compliance with ethical guidelines}

The study was approved by the Ethics Committee of the Sport Sciences Research Institute of Tehran in Iran (Code: IR.SSRC.REC.1395.466).

\section{Funding}

The present paper was extracted from the $\mathrm{PhD}$. thesis of the first author at the Department of Exercise Physiology, Sports Medicine Research Center, Sport Sciences Research Institute, Tehran, Iran. 


\section{Authors' contributions}

All authors were equally contributed in preparing this article.

\section{Conflict of interest}

The authors declared no conflict of interest.

\section{Acknowledgments}

The authors acknowledge all study participants and Tehran Sport Sciences Research Institute in Iran.

\section{References}

[1] Samavatisharif M, Neghad A, Seiavoshy H, Arji M. Comparison between two methods of supplementation with glutamine and sodium bicarbonate on CPK, LDH and CRP in non-athlete women students. International Journal of Sport Sciences. 2015; 2(3):53-9. https:// papers.ssrn.com/sol3/papers.cfm?abstract_id $=2796080$

[2] Neghad A, Seiavoshy H, Samavatisharif M. The effect of an exhaustive exercise and glutamine supplementation on $\mathrm{LDH}$ CPK and CPR indexes in non-athlete women students. International Journal of Sport Sciences. 2015; 2(3):47-52. https:/ / papers.ssrn.com/sol3/papers.cfm?abstract_id $=2796079$

[3] Neghad A, Samavatisharif MA, Seiavoshy H. The effect of an exhaustive exercise and sodium bicarbonate supplementation on LDH, CPK and CPR indexes in non-athlete women students. Marathon. 2015; 7(1):58-68. [DOI:10.2139/ ssrn.2796078]

[4] Afshari A, Samavati Sharif MA, Siavoshy H. [Comparison of speed and strength training to maintain hematological factors and Vo2 of male athletes 13 to 15 years (Persian)] Journal of Applied Exercise Physiology. 2015; 12(23):53-64. [DOI:10.22080/JAEP.2016.1308]

[5] Samavati Sharif MA, Afshari A, Siavoshy H, Keshvary M. [The effect of two exercises training on some of immune system markers in adolescent athletes (Persian)]. Journal of Practical Studies of Biosciences in Sport. 2016; 4(8):55-65. [DOI:10.22077/JPSBS.2017.453]

[6] Siavoshy H, Seddighi A. [The effects of a balance exercise program for enhancement of gait function on temporal and spatial gait parameters in young people with intellectual disabilities (Persian)]. Exceptional Education. 2016; 1(138):68-73 http://exceptionaleducation.ir/article-1-724-fa.html

[7] Siavoshy H. [Effects of two type exercise training programs on body composition of adolescence with Down syndrome (Persian)]. Exceptional Education. 2015; 3(131):65-72. http:// exceptionaleducation.ir/article-1-345-fa.html

[8] Siavoshy H, Bolurian F. The effects of 12 weeks of playing boccia on the social development of children with cerebral palsy and intellectual disability. Journal of Exceptional Children. 2016; 15(4):45-51. http://ensani.ir/fa/article/353552/
[9] Siyavoshi H. [Progressive tolerance exercises for young adults suffering from Down syndrome: A clinical experiment (Persian)]. Exceptional Education. 2013; 5(118):68-71. http:/ / exceptionaleducation.ir/article-1-31-fa.html

[10] Siavoshy H. [Effects of resistance training on salivary hormone profile and immunoglobulin a in adults with Down syndrome (Persian)]. Exceptional Education. 2016; 9(137):60-4. http://exceptionaleducation.ir/article-1-381-fa.html

[11] Siavoshy H. [Effects of exercise training on motor and cognitive abilities of three children with Down syndrome (Persian)]. Exceptional Education. 2015; 1(129):57-66. http:// exceptionaleducation.ir/article-1-348-en.html

[12] Canada, Fitness and Amateur Sport. Canadian Standardized Test of Fitness (CSTF): Operations manual. $3^{\text {rd }}$ ed. Ottawa: Government of Canada, Fitness and Amateur Sport; 1986. https://books.google.com/books?id=pfGVHAAACAAJ\&dq

[13] Reid G, Montgomery DL, Seidl C. Performance of mentally retarded adults on the Canadian Standardized Test of Fitness Canadian Journal of Public Health. 1985; 76(3):187-90. [PMID]

[14] Weller IMR, Thomas SG, Gledhill N, Paterson D, Quinney A. A study to validate the modified Canadian Aerobic Fitness test. Canadian Journal of Applied Physiology. 1995; 20(2):21121. [DOI:10.1139/h95-015] [PMID]

[15] Garcia AW, Zakrajsek JS. Evaluation of the Canadian Aerobic Fitness test with 10-to 15-year-old children. Pediatric Exercise Science. 2000; 12(3):300-11. [DOI:10.1123/pes.12.3.300]

[16] Shephard RJ, Bouchard C. A new approach to the interpretation of Canadian Home Fitness test scores. Canadian Journal of Applied Physiology. 1993; 18(3):304-16. [DOI:10.1139/ h93-026] [PMID]

[17] Pitetti KH, Fernhall B, Stubbs N, Stadler Jr LV. A step test for evaluating the aerobic fitness of children and adolescents with mental retardation. Pediatric Exercise Science. 1997; 9(2):127-35. [DOI:10.1123/pes.9.2.127]

[18] Siavoshy H, Agha Alinejad H, Kashi A, Samavati Sharif MA, Helalizadeh M. [Normative data for the Canadian Standardized Test of Fitness (CSTF) in intellectual disability students in middle schools and high schools of Hamadan Province (Persian)]. Sport Physiology. 2019; 11(42):95-112 [DOI:10.22089/SPJ.2019.6414.1816]

[19] Lee MR, Jung SM, Bang H, Kim HS, Kim YB. Association between muscle strength and type 2 diabetes mellitus in adults in Korea: Data from the Korea National Health and Nutrition Examination Survey (KNHANES) VI. Medicine. 2018; 97(23):e10984. [DOI:10.1097/MD.0000000000010984] [PMID] [PMCID]

[20] Frey GC, Chow B. Relationship between BMI, physical fitness, and motor skills in youth with mild intellectual disabilities. International Journal of Obesity. 2006; 30(5):861-7. [DOI:10.1038/sj.ijo.0803196] [PMID]

[21] Tognolo GB, Scaglia AJ, Lizana C. Relationships between physical variables, stimuli anaerobic power and muscle damage levels provided by Small-sided game in professional football players. Paper presented at: XXIII Congresso de Iniciacao Cientifica da Unicamp. 17-19 November 2015; Campinas, Brazil. [DOI:10.19146/pibic-2015-37333]

[22] Cresta Morgado P, Giorlando A, Castro M, Navigante A Relationship between weight loss and parameters of skeletal 
muscle function in patients with advanced cancer and fatigue. Supportive Care in Cancer . 2016; 24(9):3961-6. [DOI:10.1007/ s00520-016-3236-9] [PMID]

[23] Ganguly A. Levels of C-reactive protein, creatine kinasemuscle and aldolase A are suitable biomarkers to detect the risk factors for osteoarthritic disorders: A novel diagnostic protocol. Caspian Journal of Internal Medicine. 2019; 10(1):25-35. [DOI:10.22088/cjim.10.1.25] [PMID] [PMCID] 
This Page Intentionally Left Blank 